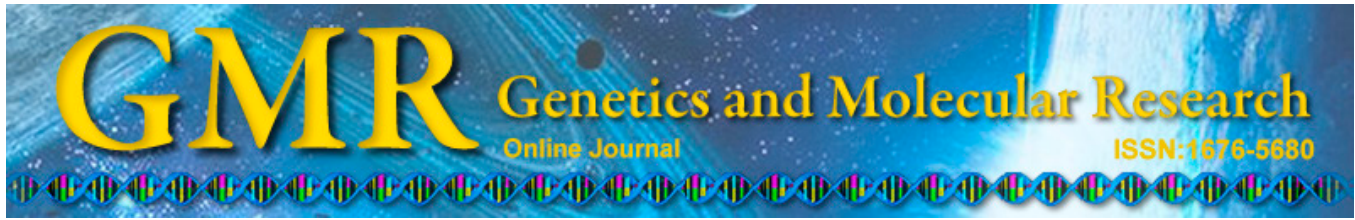

\title{
Effect of TIEG1 on apoptosis and expression of Bcl-2/Bax and Pten in leukemic cell lines
}

\author{
K. Yao' ${ }^{1}$, H.C. Xing ${ }^{2}$, B. Wu ${ }^{1}$, Y. Li ${ }^{1}$, A.J. Liao' ${ }^{1}$ W. Yang ${ }^{1}$ and Z.G. Liu ${ }^{1}$ \\ ${ }^{1}$ Hematology Department of Shengjing Hospital of China Medical University, \\ Shenyang, China \\ ${ }^{2}$ Anesthesiology Department of Central Hospital Affiliated to Shenyang \\ Medical College, Shenyang, China \\ Corresponding author: Z.G. Liu \\ E-mail: zhuogangliu@163.com
}

Genet. Mol. Res. 14 (1): 1968-1974 (2015)

Received January 9, 2014

Accepted March 25, 2014

Published March 20, 2015

DOI http://dx.doi.org/10.4238/2015.March.20.6

\begin{abstract}
We examined the effect of transforming growth factor- $\beta$ inducible early gene-1 (TIEG1) on the apoptosis of leukemic cell lines and expression of B-cell lymphoma 2 (Bcl-2) and phosphatase and tensin homolog (Pten). Four leukemic cell lines (HL-60, U937, Raji, and K562) were treated with 0, 1, 5, 10, and $20 \mathrm{ng} / \mathrm{mL}$ TIEG1, respectively. The cell growth inhibitory ratio was assessed using the MTT assay. An inhibitory curve was drawn, and half-maximal inhibitory concentration was calculated. Additionally, 1640 culture medium containing $10 \mathrm{ng} / \mathrm{mL}$ TIEG1 was used to culture leukemic cell lines for $0,6,12,24$, and $48 \mathrm{~h}$. The apoptosis of each cell line at different time points was detected by flow cytometry. Total RNA was extracted before reverse transcription-polymerase chain reaction. The products of this reaction were analyzed by electrophoresis, and the expression of Bcl-2/Bcl-2-associated X protein (Bax) and Pten were detected. After treatment with TIEG1, proliferation of the 4 leukemic cell lines was inhibited both time- and dose-dependently. During apoptosis induction, the expression of Bcl-2 was decreased and the expressions of Bax and Pten were increased in the 4 leukemic cell
\end{abstract}


lines induced by TIEG1 $(\mathrm{P}<0.05)$. TIEG1 can inhibit the proliferation of leukemic cells and induce their apoptosis in a time- and dosedependent manner. A close relationship exists between Bcl-2/Bax and Pten expression and cell apoptosis induced by TIEG1.

Key words: Apoptosis; Bcl-2/Bax; Leukemic cells; Pten; TIEG1

\section{INTRODUCTION}

Transforming growth factor- $\beta$ inducible early gene-1 (TIEG1), also known as Kruppel-like factor 10 , is a TGF- $\beta 1$-inducible early gene and was first detected in fetal osteoblasts using a polymerase chain reaction (PCR) assay. The TIEG1 gene encodes a 72-kD protein of 480 amino acids and is located on chromosome band 8q22.2.TIEG1. The gene product is a transcription factor that regulates the expression of genes related to cell growth and differentiation (Reinholz et al., 2004). Recent studies have indicated that the over-expression of TIEG1 is correlated with tumor development. The expression of TIEG1 was increased in malignant tumor tissues, including breast, pancreatic, and liver cancers, among others (Jiang et al., 2011; Jiang et al., 2012; Jin et al., 2012; Song et al., 2012). Various anticancer drugs that upregulate the expression of TIEG1 to induce cell apoptosis have been used to treat leukemia (Jin et al., 2004; Dosen-Dahl et al., 2008). These results of previous studies indicate that TIEG1 may inhibit cell proliferation and induce cell apoptosis when it is over-expressed; however, this hypothesis requires further study.

The B-cell lymphoma 2 (Bcl-2) family is widely distributed in many organisms and can be either pro-apoptotic [Bcl-2-associated X protein (Bax), Bcl-2-associated death promoter, Bcl-2 homologous antagonist killer (Bak), and Bcl-2-related ovarian killer, among others] or anti-apoptotic (Bcl-2, Bcl-xL, and Bcl-w, among others), and play an important role in mediating cell apoptosis. During tumor cell apoptosis, a correlation has been demonstrated between TIEG1 and Bcl-2/Bax, but the exact mechanism remains unknown (Duenker et al., 2005). Phosphatase and tensin homolog (Pten) acts as a tumor suppressor gene; its phosphatase protein product has been shown to have dual antitumor function (Dahia et al., 1999). Moreover, low expression of Pten may inhibit cell growth. Mutations or deletions of the Pten gene occur in most tumors, including breast carcinoma, prostatic carcinoma, endometrioid carcinoma, and glioblastoma, but low expression or deletion of Pten has been observed in leukemia (Dahia et al., 1999; Yilmaz et al., 2006).

In this study, we investigated the effect of TIEG1 on the HL-60, U937, K562, and Raji4 cell lines and determined the expression of Bcl-2 and Pten.

\section{MATERIAL AND METHODS}

\section{Cell culture}

The HL-60, U973, and Raji cell lines (Boster Co., Wuhan, China) were cultured in a medium containing 10\% fetal calf medium. K562 cell lines were cultured in 10\% fetal serum medium. All cell lines were cultured in a humidified incubator at $37^{\circ} \mathrm{C}$ under $5 \% \mathrm{CO}_{2}$ and passaged every 3 days. All cell lines were grown to log phase. The cell concentration was 5.0 x $10^{4}$ cells $/ \mathrm{mL}$. 


\section{MTT assay}

Four different leukemia cell lines were seeded into 96-well plates ( $1 \times 10^{4}$ cells/well) and $0,1,5,10$, or $20 \mathrm{ng} / \mathrm{mL}$ TIEG1 (Abcam Company, Hong Kong) was added to 1640 medium. The cells were grown at $37^{\circ} \mathrm{C}$ for $0,6,12,24$, and $48 \mathrm{~h}$. The $5 \mathrm{mg} / \mathrm{mL} 20 \mu \mathrm{L}$ MTT was added to the supernatant followed by incubation of the sample at $37^{\circ} \mathrm{C}$ for $4 \mathrm{~h}$ in an incubator. After centrifugation ( $100 \mathrm{~g}$ ) for $10 \mathrm{~min}$, the supernatant was discarded, and $200 \mu \mathrm{L}$ dimethyl sulfoxide was added. The OD value at a wavelength of $490 \mathrm{~nm}$ was measured using a microplate reader. The inhibitory ratio was calculated as follows: inhibitory ratio $=(\mathrm{A}$ control group- A test group)/A control group x $100 \%$, the half maximal inhibitory concentration $\left(\mathrm{IC}_{50}\right)$ was calculated using this formula.

\section{Flow cytometry}

All cell lines were cultured in 1640 medium with $10 \mathrm{ng} / \mathrm{mL}$ TIEG1. Cells were collected at $0,6,12,24$, and $48 \mathrm{~h}$. All tubes were centrifuged for $5 \min (12000 \mathrm{~g})$, washed 2 times with phosphate-buffered saline, and then centrifuged for $5 \mathrm{~min}$ in tubes containing $500 \mu \mathrm{L}$ binding buffer. The cells were then treated with $5 \mu \mathrm{L}$ Annexin-V-fluorescein isothiocyanate and stained with $5 \mu \mathrm{L}$ propidium iodide, followed by incubation at $37^{\circ} \mathrm{C}$ for $10 \mathrm{~min}$ in the dark. Samples were analyzed using a flow cytometer according to manufacturer instructions. All time point experiments were repeated 3 times.

\section{RT-PCR}

All cell lines were cultured in 1640 medium containing $10 \mathrm{ng} / \mathrm{mL}$ TIEG1, and cells were collected at $0,6,12,24$, and $48 \mathrm{~h}$. After total RNA extraction, RNA samples were subjected to reverse transcription-PCR (RT-PCR) and amplified products were analyzed by gel electrophoresis.

Primers sequences were as follows: Bcl-2: 5'-CAAGTGTTCCGCGTGATTG AA-3' (sense) and 5'-CCCGGTTATCGTACCCTGTTC-3' (antisense); Bax: 5'-CTCAG GATGCGTC ACCAAGAA-3' (sense) and 5'-AACCCGGCCCCAGTTGAAGT T-3' (antisense); Pten: 5'-TACAATTTCGGGCACCGCATAT-3' (sense) and 5'-AACCCT CATTCAGACCTTCACA T-3' (antisense). Primers were synthesized by Shanghai Bio-Engineering Company (Shanghai, China). PCR conditions were as follows: $95^{\circ} \mathrm{C}$ for $5 \mathrm{~min}$, followed by 30 cycles at $95^{\circ} \mathrm{C}$ for $20 \mathrm{~s}$, and $60^{\circ} \mathrm{C}$ for $20 \mathrm{~s}$, with extension at $72^{\circ} \mathrm{C}$ for $5 \mathrm{~min}$. Amplified products were visualized using a UVP BioSpectrum device (Upland, CA, USA) following 1.5\% agarose gel electrophoresis. All experiments were repeated 3 times.

\section{Statistical analysis}

Statistical analysis was performed using the SPSS 17.0 software (SPSS, Inc., Chicago, IL, USA) and all results are reported as means \pm standard deviation (SD). One-way analysis of variance was used to compare groups. A P-value $<0.05$ was considered to be statistically significant. 


\section{RESULTS}

\section{Cell proliferation}

TIEG1 inhibited the proliferation of the 4 leukemia cell lines proliferation in a doseand time-dependent manner $(\mathrm{P}<0.05)$. All leukemia cell lines curves are shown in Figure 1 as determined using the MTT method. The $\mathrm{IC}_{50}(\mathrm{ng} / \mathrm{mL})$ values of leukemia cells at different time points are presented in Table 1.
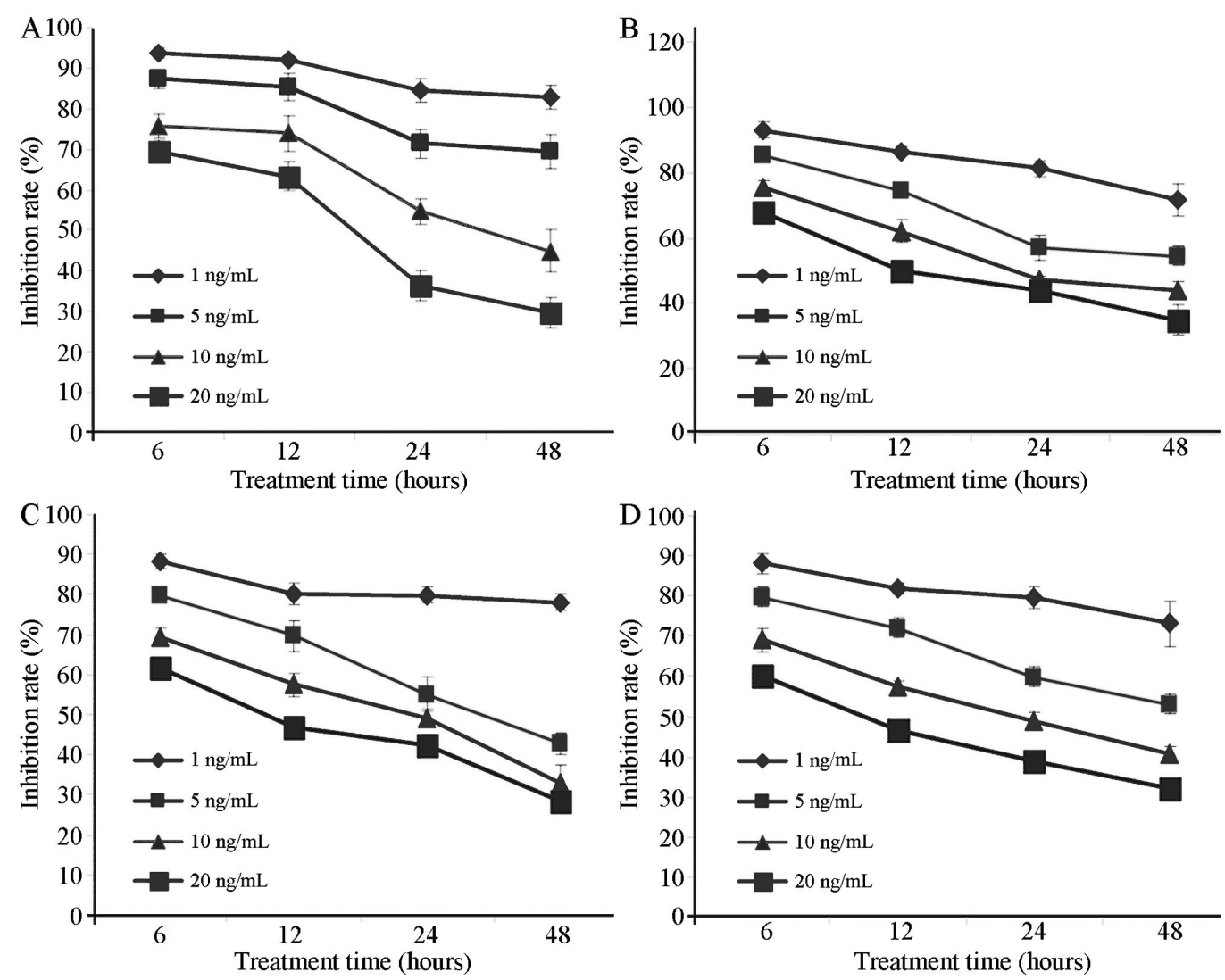

Figure 1. Inhibitory effect of 4 leukemia cell lines treated with TIEG1. A. Inhibitory effect of HL-60 cells treated with TIEG1. B. Inhibitory effect of U937 cells treated with TIEG1. C. Inhibitory effect of Raji cells treated with TIEG1. D. Inhibitory effect of K562 cells treated with TIEG1.

\section{Table 1. $\mathrm{IC}_{50}(\mathrm{ng} / \mathrm{mL})$ of leukemia cells at different time points.}

\begin{tabular}{ccccr}
\hline Time $(\mathrm{h})$ & HL-60 & U937 & Raji & K562 \\
\hline 6 & 71.32 & 69.33 & 54.32 & 48.19 \\
12 & 54.77 & 22.27 & 18.23 & 18.72 \\
24 & 12.03 & 10.02 & 9.76 & 9.50 \\
48 & 8.45 & 6.35 & 4.53 & 3.85 \\
\hline
\end{tabular}




\section{Cell apoptosis}

Based on the results of the MTT assay, the 4 leukemia cell lines treated with TIEG1 $(10 \mathrm{ng} / \mathrm{mL})$ showed different rates of cell apoptosis at $6,12,24$, and $48 \mathrm{~h}$. The apoptosis rates of the different groups were compared (Table 2), and all groups showed a significant difference $(\mathrm{P}<0.05)$, except for one group.

Table 2. Apoptosis rate of leukemia cells at different time points ( $\%$, means $\pm \mathrm{SD}, \mathrm{N}=3)$.

\begin{tabular}{lcrrr}
\hline Time $(\mathrm{h})$ & HL-60 & U937 & \multicolumn{1}{c}{ Raji } & K562 \\
\hline 0 & $4.70 \pm 0.87 *$ & $2.03 \pm 0.28 *$ & $2.21 \pm 0.35 *$ & $2.13 \pm 0.42$ \\
6 & $5.34 \pm 0.71 *$ & $2.54 \pm 0.52 *$ & $2.38 \pm 0.73 *$ & $7.79 \pm 0.71$ \\
12 & $8.32 \pm 0.68$ & $10.88 \pm 0.46$ & $2.92 \pm 1.42$ & $11.17 \pm 1.37$ \\
24 & $15.16 \pm 1.64$ & $27.11 \pm 0.79$ & $26.12 \pm 1.57$ & $24.66 \pm 0.29$ \\
48 & $19.92 \pm 0.95$ & $62.32 \pm 1.35$ & $52.59 \pm 0.89$ & $48.60 \pm 1.38$ \\
\hline \multicolumn{2}{l}{ All groups showed a significant difference $(\mathrm{P}<0.05)$, except for one group (marked with an asterisk). }
\end{tabular}

\section{mRNA expression of Bcl-2, Bax, and Pten genes}

Four leukemia cell lines were treated with TIEG1 $(10 \mathrm{ng} / \mathrm{mL})$ and total cell RNA was extracted at $6,12,24$, and $48 \mathrm{~h}$. Total RNA concentration was determined using an ultraviolet spectrophotometer. The relative mRNA expression of the Bcl-2, Bax, and Pten gene was measured using gray-scale analysis. The results showed that the mRNA expression of Bcl-2 was decreased, but the mRNA expression of Bax and Pten was increased (Table 3).

Table 3. mRNA expression level of Bcl-2, Bax, and Pten detected by RT-PCR.

\begin{tabular}{cccccc}
\hline Gene & Time $(\mathrm{h})$ & HL-60 & U937 & Raji & K562 \\
\hline Bcl-2 & 0 & $1.00 \pm 0.00$ & $1.00 \pm 0.00$ & $1.00 \pm 0.00$ & $1.00 \pm 0.00$ \\
& 6 & $0.83 \pm 0.11$ & $0.81 \pm 0.32$ & $0.81 \pm 0.32$ & $0.76 \pm 0.34$ \\
& 12 & $0.78 \pm 0.23$ & $0.65 \pm 0.18$ & $0.48 \pm 0.18$ & $0.56 \pm 0.29$ \\
& 24 & $0.72 \pm 0.28$ & $0.43 \pm 0.17$ & $0.31 \pm 0.16$ & $0.38 \pm 0.21$ \\
Bax & 48 & $0.63 \pm 0.12$ & $0.19 \pm 0.09$ & $0.13 \pm 0.03$ & $0.21 \pm 0.11$ \\
& 0 & $1.00 \pm 0.00$ & $1.00 \pm 0.00$ & $1.00 \pm 0.00$ & $1.16 \pm 0.18$ \\
& 6 & $1.17 \pm 0.18$ & $1.21 \pm 0.39$ & $1.38 \pm 0.41$ & $1.06 \pm 0.37$ \\
& 12 & $1.85 \pm 0.21$ & $1.48 \pm 0.18$ & $1.59 \pm 0.24$ & $1.42 \pm 0.19$ \\
Pten & 24 & $2.52 \pm 0.16$ & $2.11 \pm 0.36 \pm 0.19$ & $1.76 \pm 0.38$ \\
& 48 & $1.71 \pm 0.33$ & $1.00 \pm 0.00$ & $1.00 \pm 0.00$ & $1.00 \pm 0.00$ \\
& 0 & $1.00 \pm 0.00$ & $1.34 \pm 0.43$ & $1.68 \pm 0.17$ & $1.18 \pm 0.42$ \\
& 6 & $1.58 \pm 0.31$ & $1.59 \pm 0.23$ & $2.07 \pm 0.33$ & $1.41 \pm 0.32$ \\
& 12 & $1.88 \pm 0.27$ & $1.95 \pm 0.33$ & $2.55 \pm 0.21$ & $1.68 \pm 0.19$ \\
\hline
\end{tabular}

$\mathrm{P}<0.05$, compared between groups of one type of leukemia cells.

\section{DISCUSSION}

Many biological functions of TIEG1 remain unclear. TIEG1 inhibits cell proliferation and induces apoptosis. Over-expression of exogenous TIEG1 rather than endogenous TIEG1 induced by TGF- $\beta$ was shown to increase the activity of alkaline phosphatase and decrease mRNA and protein levels of osteocalcin, as well as suppress cell growth in the osteosarcoma cell model transfected with TIEG1 (Hefferan et al., 2000). Previous studies detected higher TIEG1 protein expression in normal mammary epithelial cells than in breast tumor cells; 
moreover, TIEG1 protein was not expressed in infiltrative tumor cells, indicating that TIEG1 plays an inhibitory role in regulating tumor growth (Subramaniam et al., 1998).

There have been some studies to examine the effect of TIEG1 on hematological tumor cells. The expression of TIEG1 was clearly increased in leukemia cell apoptosis, implying that TIEG1 inhibits leukemia cell proliferation and induces cell apoptosis. Our previous study demonstrated that the expression of TIEG1 was gradually enhanced during HL-60 apoptosis induced by TGF- $\beta 1$. In this study, we found that TIEG1 induced apoptosis in 4 different leukemia cell lines, including HL-60, U973, Raji, and K562, in a dose-and time-dependent manner. This suggests that TIEG1 inhibits leukemia cell to induce cell apoptosis.

Bcl-2 is central to the regulation of apoptosis, a process vital for proper tissue development and cellular homeostasis. Members of the Bcl-2 protein family are critical regulators of apoptosis and include 3 subgroups of proteins that either promote cell survival or initiate cell death. The possible mechanisms of Bcl-2 induction of apoptosis involve the release of intracellular $\mathrm{Ca}^{2+}$, oxygen free radical metabolism, and signal transduction, among others (Mathai et al., 2005; Brooks and Dong, 2007). The BCL2 family of proteins is composed of both anti- and pro-apoptotic proteins. Anti-apoptotic BCL2 proteins such as BCL2 and Bcl$\mathrm{xL}$ induced myeloid leukemia cell differentiation protein 1, and $\mathrm{Bcl}-2$-associated athanogene 1 in mammals share 4 BCL2 homology or 'BH' domains (BH1-BH4). Pro-apoptotic BCL2 proteins (such as bax, Bak, Bcl-2-associated death promoter, and Bcl-xs) can be separated into 2 subclasses: the Bax-like proteins (such as Bax and Bak in mammals - no Bax-like proteins have been identified in Caenorhabditis elegans), which contain 3 BH domains (BH1-BH3) and the BH3-only proteins (such as Puma or Noxa in mammals and EGL-1 in C. elegans), which contain a single $\mathrm{BH}$ domain (BH3). After replacing important amino acids in the $\mathrm{BH}$ domains (BH1-BH3) of Bcl-2, Bcl-2 lost its anti-apoptosis function; additionally, mutational Bcl-2 molecules formed homodimers with themselves, but did not form heterodimers with Bax. This indicated that Bcl-2 inhibited apoptosis to protect against cell survival by forming heterodimers with Bax to prevent its release (Cory and Adams, 2002). It was confirmed that Bcl-2 and Bax are associated with apoptosis in many tumor cells and are apoptosis-related factors in tumor cells. Various studies have also provided evidence that a correlation exists between TIEG1 and Bcl-2/Bax, but the exact mechanism remains unclear (Duenker et al., 2005).

Pten, the first tumor suppressor gene, was discovered in the phosphatase family and was shown to block signaling pathways by activating protein phosphatase and lipid phosphatase to inhibit tumor cell growth, invasion, and metastasis (Myers et al., 1997; Tamura et al., 1998). Conditionally deleting the Pten tumor suppressor gene was found to cause myeloproliferative disease within days and transplantable leukemia within weeks, while Pten deletion promoted hematopoietic stem cell proliferation. Thus, Pten plays a critical role in distinguishing between leukemia stem cells and hematopoietic stem cells (Yilmaz et al., 2006). In a hematopoietic system, malignant tumors (e.g., leukemia, lymphoma, and myeloma), low expression, or deletion of the Pten gene or protein was related to poor patient prognosis ( $\mathrm{Wu}$ et al., 2012). Furthermore, the Pten gene was inactivated by transcriptional silencing, posttranscriptional modification, and methylation (Xu et al., 2003; Yang et al., 2007).

Various studies have confirmed that Bcl-2/Bax and Pten are associated with apoptosis of many tumor cells and are apoptosis-related factors in tumor cells. In this study, we observed decreased Bcl-2 expression and increased Bax and Pten expression induced by TIEG1 in 4 different leukemia cell lines. These results demonstrate that Bcl-2/Bax is related to leukemia cell apoptosis induced by TIEG1, but the details regarding this process require further investigation. 


\section{REFERENCES}

Brooks C and Dong Z (2007). Regulation of mitochondrial morphological dynamics during apoptosis by Bcl-2 family proteins: a key in Bak. Cell Cycle 6: 3043-3047.

Cory S and Adams JM (2002). The Bcl-2 family: regulators of the cellular life-or-death switch. Nat. Rev. Cancer 2: 647656.

Dahia PL, Aguiar RC, Alberta J, Kum JB, et al. (1999). PTEN is inversely correlated with the cell survival factor Akt/ PKB and is in activated via multiple mechanisms in haematological malignancies. Hum. Mol. Genet. 8: 185-193.

Dosen-Dahl G, Munthe E, Nygren MK, Stubberud H, et al. (2008). Bone marrow stroma cells regulate TIEG1 expression in acute lymphoblastic leukemia cells: role of TGFbeta/BMP-6 and TIEG1 in chemotherapy escape. Int. J. Cancer 123: 2759-2766.

Duenker N, Valenciano AI, Franke A, Hernández-Sánchez C, et al. (2005). Balance of pro-apoptotic transforming growth factor-beta and anti-apoptotic insulin effects in the control of cell death in the postnatal mouse retina. Eur. J. Neurosci. 22: 28-38.

Hefferan TE, Reinholz GG, Rickard DJ, Johnsen SA, et al. (2000). Overexpression of a nuclear protein, TIEG, mimics transforming growth factor-beta action in human osteoblast cells. J. Biol. Chem. 275: 20255-20259.

Jiang L, Wang F, Lin F, Gao SM, et al. (2011). Lentivirus-mediated overexpression of TGF- $\beta$ inducible early gene 1 inhibits SW1990 pancreatic cancer cell growth. Cell Biol. Int. 35: 891-896

Jiang L, Lai YK, Zhang JF, Chan CY, et al. (2012). Transactivation of the TIEG1 confers growth inhibition of transforming growth factor- $\beta$-susceptible hepatocellular carcinoma cells. World J. Gastroenterol. 18: 2035-2042.

Jin W, Qu LF, Min P, Chen S, et al. (2004). Identification of genes responsive to apoptosis in HL-60 cells. Acta Pharmacol. Sin. 25: 319-326.

Jin W, Chen BB, Li JY, Zhu H, et al. (2012). TIEG1 inhibits breast cancer invasion and metastasis by inhibition of epidermal growth factor receptor (EGFR) transcription and the EGFR signaling pathway. Mol. Cell. Biol. 32: 50-63.

Mathai JP, Germain M and Shore GC (2005). BH3-only BIK regulates BAX, BAK-dependent release of $\mathrm{Ca}^{2+}$ from endoplasmic reticulum stores and mitochondrial apoptosis during stress-induced cell death. J. Biol. Chem. 280: 23829-23836.

Myers MP, Stolarov JP, Eng C, Li J, et al. (1997). P-TEN, the tumor suppressor from human chromosome 10q23, is a dual-specificity phosphatase. Proc. Natl. Acad. Sci. U S A 94: 9052-9057.

Reinholz MM, An MW, Johnsen SA, Subramaniam M, et al. (2004). Differential gene expression of TGF beta inducible early gene (TIEG), Smad7, Smad2 and Bard1 in normal and malignant breast tissue. Breast Cancer. Res. Treat. 86: 75-88.

Song KD, Kim DJ, Lee JE, Yun CH, et al. (2012). KLF10, transforming growth factor- $\beta$-inducible early gene 1, acts as a tumor suppressor. Biochem. Biophys. Res. Commun. 419: 388-394.

Subramaniam M, Hefferan TE, Tau K, Peus D, et al. (1998). Tissue, cell type, and breast cancer stage-specific expression of a TGF-beta inducible early transcription factor gene. J. Biol. Chem. 68: 226-236.

Tamura M, Gu J, Matsumoto K, Aota S, et al. (1998). Inhibition of cell migration, spreading, and focal adhesions by tumor suppressor PTEN. Science 280: 1614-1617.

Wu B, Wang X, Chi ZF, Hu R, et al. (2012). Ursolic acid-induced apoptosis in K562 cells involving upregulation of PTEN gene expression and inactivation of the PI3K/Akt pathway. Arch. Pharm. Res. 35: 543-548.

Xu Q, Simpson SE, Scialla TJ, Bagg A, et al. (2003). Survival of acute myeloid leukemia cells requires PI3 kinase activation. Blood 102: 972-980.

Yang J, Liu J, Zheng J, Du W, et al. (2007). A reappraisal by quantitative flow cytometry analysis of PTEN expression in acute leukemia. Leukemia 21: 2072-2074.

Yilmaz OH, Valdez R, Theisen BK, Guo W, et al. (2006). Pten dependence distinguishes haematopoietic stem cells from leukaemia-initiating cells. Nature 441: 475-482. 